\title{
Trends of Clinical Practice for Obstructive Sleep Apnea Following the Change in the National Health Insurance Coverage
}

\author{
Moonjeong Kim, Hyunjeong Baek, Seo-Young Lee \\ Health Data Laboratory, School of Medicine, Kangwon National University, Chuncheon, Korea \\ 국민건강보험 급여화에 따른 수면무호흡증 관련 진료 현황 \\ 김문정, 백현정, 이서영 \\ 보건의료빅데이터 연구실, 강원대학교 의학전문대학원
}

$\begin{array}{ll}\text { Received } & \text { October 12, } 2020 \\ \text { Revised } & \text { October 19, } 2020 \\ \text { Accepted } & \text { October 20, } 2020\end{array}$

Address for correspondence Seo-Young Lee, MD, PhD Department of Neurology, Kangwon National University Hospital, 156 Baengnyeong-ro Chuncheon 24289, Korea

Tel: $+82-33-258-2431$

Fax: $+82-33-258-2103$

E-mail: leeseoyoung@kangwon. ac.kr
Objectives: We aimed to investigate the recent changes in clinical practice in Korea after the introduction of the national health insurance coverage for polysomnography and positive airway pressure (PAP) treatment for obstructive sleep apnea syndrome (OSAS) in July 2018. Methods: We assessed the amount, cost, and geographic distribution of healthcare utilization associated with the diagnostic codes of sleep apnea, polysomnography tests, and PAP treatment using the Korea National Health Insurance Database. Furthermore, the specialties of the prescribing physician and the type of health institute were investigated. Results: The number of patients who used health resources under the diagnostic codes of sleep apnea has increased since 2018. In total, 81,016 polysomnography tests were performed from July 2018 to December 2019, and 58,213 patients underwent PAP treatment from July 2018 to March 2020. The total medical cost associated with sleep apnea was 56,517,061 thousand won in 2019. Auto-titrating PAP accounted for $85.1 \%$ of all PAP devices prescribed, and the overall adherence rate for PAP was 69.3\%. PAP was prescribed most frequently in private clinics (49.9\%) and mostly by physicians of ear-nose-throat (66.6\%), neurology (18.7\%), and psychiatry (10.3\%) specializations. PAP was used more frequently by those living in urban areas than by those living in rural areas. Conclusions: Recent changes in the national health insurance coverage have resulted in a surge in the healthcare utilization related to OSAS. There was a regional variation in OSAS treatment, suggesting an inequality in the availability of healthcare for OSAS and the need to improve the awareness regarding OSAS.

J Sleep Med 2020;17(2):122-127 Non-invasive ventilation; National health insurance.

\section{서 론}

폐쇄성 수면무호흡증(obstructive sleep apnea syndrome, OSAS)은 수면 중 기도가 반복적으로 좁아지거나 폐쇄되어 호흡이 정지하거나 감소되는 증상으로 비교적 흔한 질환으 로 알려져 있다. OSAS를 Apnea-Hypopnea Index(AHI) $\geq 5$ 이면서 과도한 주간 졸림을 동반한 경우로 정의할 때, 그 유 병률은 남성에서 6\%(범위, 3 18\%), 여성에서 4\%(범위, 1

This is an Open Access article distributed under the terms of the Creative Commons Attribution Non-Commercial License (https://creativecommons.org/licenses/by-nc/4.0) which permits unrestricted non-commercial use, distribution, and reproduction in any medium, provided the original work is properly cited.
17\%)로 보고되었다. ${ }^{1} \mathrm{OSAS}$ 는 수면 중에 잦은 코골이와 각성 을 동반하고, 위식도역류, 야뇨 등의 문제를 일으키기도 한다. 또한, 주간에는 과도한 주간 졸림, 피로, 인지 장애가 나타나 고, 이로 인해 교통사고와 직장 내 사고가 증가된다. OSAS가 지속될수록 심뇌혈관 질환의 발병 가능성이 높아지고, 급사 의 위험이 증가한다. ${ }^{2}$

따라서, OSAS를 진단하고 치료하는 것은 보건의료 측면 에서도 중요성을 지닌다. OSAS의 치료법은 크게 상기도 양 압 치료(postive airway pressure, PAP), 구강 내 장치, 수술이 있으며, 그 중 PAP 치료는 중등도에 상관없이 효과가 가장 좋은 표준 치료법이다. ${ }^{3}$ 그러나, 국내에서 OSAS에 대한 검사 
및 치료가 국민건강보험 급여가 되지 않아, 40 80만 원의 수 면다원검사비와 200만 원 내외의 PAP 기기 구매 비용의 부 담으로 진료를 포기하는 환자의 비율이 높았다. 2018년 7월 2일부터 국민건강보험에서 OSAS에 대한 수면다원검사와 $\mathrm{PAP}$ 에 대한 지원을 시작하면서, 환자는 비용의 $20 \%$ 만 부담 할 뿐만 아니라 PAP 기기를 임대하는 방식으로 월 2만 원 내외에 이용할 수 있게 되었다. 더불어, 적응을 못 할 경우 손 해 없이 치료를 중지할 수 있게 되었다. 따라서, OSAS 진료 의 급증과 수면 의료계의 지각변동이 예상되었다.

본 연구에서는 국민건강보험 급여 전환 이후 OSAS의 진 단 및 치료의 변화와 현황을 파악하고자 한다.

\section{방 법}

\section{자료원}

OSAS의 진료 현황은 국민건강보험 청구 자료를 통해 획 득하였고, 인구 정보는 통계청 인구총조사 자료 또는 주민등 록 인구 통계를, 전문의 현황은 건강보험 통계 자료를 활용 하였다.

OSAS의 진료와 수면다원검사 건수 통계는 보건의료 빅데 이터개방시스템 ${ }^{4}$ 을 통해 산출하였다. OSAS의 진료는 International Classification of Disease 10th revision 코드로 G473(sleep apnea)으로 판별하였고, 수면다원검사는 건강보 험 행위 분류 F6290(수면다원검사)으로 검색하였다. PAP 등 록 환자 현황은 국민건강보험공단의 정보공개청구 시스템을 통해 얻었다. 2019년 이전의 인구를 위한 인구총조사와 전 문의 통계는 국가통계포털에서 구했다. ${ }^{5} 2020$ 년 인구는 행 정안전부 주민등록 통계를 활용하였다. ${ }^{6}$ 인구 대비 수면다원 검사 건수 및 PAP 치료 환자 수를 산출하기 위해 2019년 연 령 및 성별 또는 시군구별 자료를 활용하였다. ${ }^{6}$

\section{산출 지표}

수면무호흡을 주 진단으로 2010년 1월 1일 2019년 12월 31일까지 진료받은 연간 성별 및 연령별 수진자 수와, 2018년
1월 1일 2019년 12월 31일까지 연간 수진 비용을 집계하였 다. 수면다원검사는 2018년 7월 2일 12월 31일까지, 2019년 1월 1일 12월 31일까지의 각각 시행 건수와 비용을 산출하 였다.

PAP 등록 환자 수(연도별, 성별, 연령별, 요양기관종별, 진료 과목별, 지역별), 순응 실패 환자 수는 2018년 7월 2일 국민건강보험 급여 시작 시점부터 2020년 3월 31일까지의 인원을 집계하였고, PAP 기종에 따른 수진자수, PAP 지급 금액은 2018, 2019년 연도별로 산출하였다.

인구 대비 수면 무호흡 진료, 수면다원검사 건수 및 PAP 치료 환자 수를 2019년 연령 및 성별 또는 시군구별로 산출 하였다. 거주지역별 PAP 치료 환자 수는 2020년 1분기 기준 으로 산출된 지역별 전문의 수와의 상관 관계(Pearson 상관 분석)를 분석하였다. 통계 프로그램은 SPSS version 22(IBM Corp., Armonk, NY, USA)을 이용하였고, $p$-values는 0.05 미만일 때 유의하다고 판단하였다.

\section{결 과}

수면무호흡으로 진단받은 환자 수는 2010년 19,780명에서 2017년 31,377명으로 완만한 증가 추세를 보이다가, 건강보험 급여화가 시작된 이후에는 2018년 45,067명, 2019년 83,638명 으로, 급격한 증가 추세를 보였다(Fig. 1). 수면무호흡증과 관 련된 국민건강보험 요양 급여 총액은 2018년에 20,223,653 천 원, 2019년에 56,517,061천 원이었다.

수면다원검사 건수는 2018년 16,046명, 2019년 64,970명이 었다. 수면다원검사로 인한 진료 금액은 2018년 9,173,231천 원, 2019년 40,355,587천 원이었다.

2018년 7월 2일 2020년 3월 31일 동안 등록된 PAP 환자 수는 58,213명이었다. 이 중 3 개월 후 재처방까지 하루 4시간 이상 사용 일수가 $70 \%$ 에 못 미친 환자 수는 17,879 명으로, 전체 환자 수 대비 $30.7 \%$ 를 차지하였다. PAP의 종류별로 살 펴보면 자동형 PAP(auto titrating positive airway pressure, $\mathrm{APAP})$ 의 사용이 $85.1 \%$ 로 가장 많았다. 연도별 PAP 등록

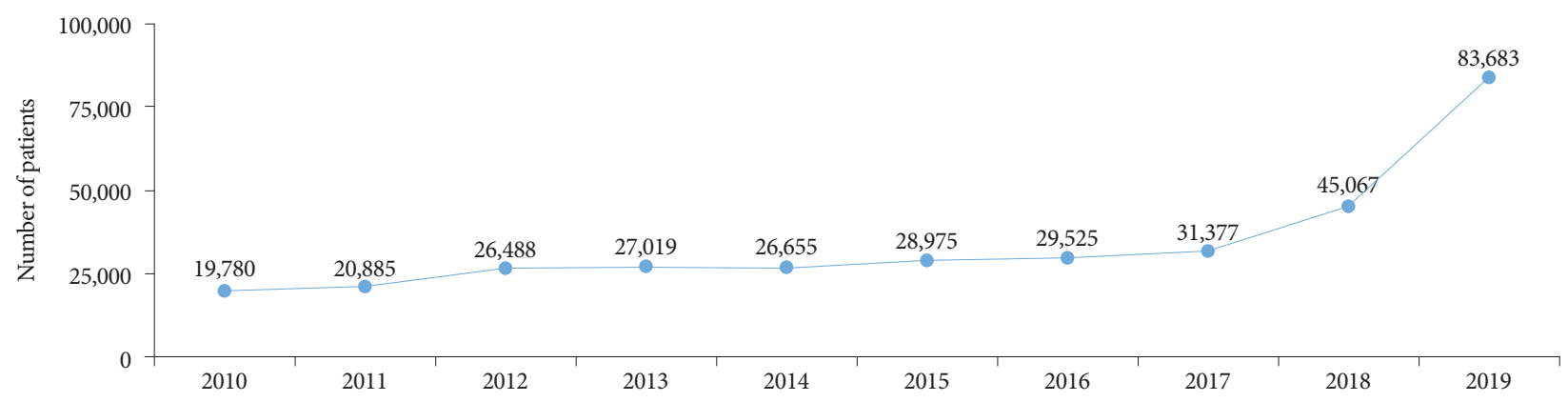

Figure 1. Annual number of patients who used health resources under the diagnosis of sleep apnea. 
환자 수는 2018년 12,624명, 2019년 39,200명이었다(Table 1). PAP 관련 지급 금액은 연도별로 2018년 1,619백만 원, 2019 년 18,359 백만 원이었다.

수면다원검사 환자 수와 PAP 등록 환자 수는 남성이 여 성보다 많았다. 수면다원검사 환자 수는 남성 30 40대, 여성 50 60대에서 가장 많았고, PAP 등록 환자 수는 남성 30 50 대, 여성 50 60대에서 많았다. OSAS로 진료받은 환자 수를 총인구 대비로 보았을 때, 남자가 여자보다 10배 이상 많고, 남자 30 50대, 여자 50 60대에서 많았다. 국내의 중등도 OSAS(AHI $\geq 15$ ) 환자 수를 20 39세는 외국 유병률 데이터, ${ }^{7}$ 40 69세는 국내 유병률 데이터로부터 우리나라 인구에 적용 해 추정하면, 8 20 69세 남성 1,994,520명, 30 69세 여성에서 644,323 명이다. 이에 비해, 20 69세 남성의 3.2\%, 30 69세 여 성에서 1.9\%의 OSAS 환자가 2018년 7월 2일 2020년 3월

Table 1. Annual number of the patients who received PSG study and PAP treatment

\begin{tabular}{lrr}
\hline & $2018^{*}$ & \multicolumn{1}{c}{$2019^{\dagger}$} \\
\hline PSG & 16,046 & 64,970 \\
PAP & 12,624 & 39,200 \\
CPAP & 1,054 & 5,334 \\
APAP & 6,496 & 37,646 \\
BiPAP & 8 & 32 \\
\hline
\end{tabular}

*2018 represents between July 2 (the time when national health insurance coverage for PSG and PAP began) and Dec 31 in 2018, †2019 represents between January 1 and December 31 in 2019. PSG: polysomnography, PAP: postive airway pressure, CPAP: continuous PAP, APAP: auto-titrating PAP, BiPAP: bi-level PAP
31일 동안 PAP 치료를 받은 것으로 추정된다(Table 2).

처방전 발행 요양기관의 지역 소재지별로 살펴보면, 지역별 인구 대비 지급 건수가 가장 많은 곳은 서울이었다(Table 3).

환자 거주지 기준으로 보면, 지역별 인구 대비 PAP 등록 환자 수는 전국 평균 1,000 명당 1.14 명이었다. 전국 평균 대 비 PAP 등록 환자 수가 높은 곳은 경기도, 서울특별시, 세종 특별자치시, 제주도였다(Fig. 2). 시군구별로 살펴보면, 거주 지별 인구 대비 PAP 환자 수는 지역 내 인구 대비 이비인후 과 전문의 숫자와 유의한 연관성이 있었다(Pearson 상관 계 수 $=0.46, p<0.001$.

환자 등록 요양기관종별로 비교해 보면, 의원에서 환자 등 록이 29,469명으로 총 인원의 $49.9 \%$ 를 차지했다. 상급종합병 원은 16,158 명으로 두 번째로 많은 수를 차지하였다. 전문 진 료과목별로는, 이비인후과에서 39,347 명으로 총인원의 $66.6 \%$ 를 차지하였고, 신경과, 정신과, 내과 순으로 많은 환자가 등 록하였다. 각 과별 전문의 1 인당 PAP 처방 환자 수도 이비인 후과, 신경과, 정신과, 내과 순이었다(Table 4, 5).

\section{고 찰}

수면무호흡증으로 진단받은 환자 수는 2010 2017년에 비 해 2018, 2019년에 급증하였다. 2019년에 2018년 대비 수면 다원검사를 받은 환자는 4배, PAP 등록 환자는 3.11배 증가 하였다. PAP 등록 환자 중 순응 실패는 $30.7 \%$ 이고 전체 PAP 처방 중 APAP이 $85.1 \%$ 를 차지하였다. PAP 처방은 환자의 거주지나 요양기관의 소재지 모두 서울, 경기도에 집중되어

Table 2. The number of patients who used health resource related with sleep apnea according to age and sex

\begin{tabular}{|c|c|c|c|c|c|c|c|c|}
\hline \multirow{2}{*}{ Age (year) } & \multicolumn{2}{|c|}{ PSG $^{*}$} & \multicolumn{2}{|c|}{$\mathrm{PAP}^{\dagger}$} & \multicolumn{2}{|c|}{ Sleep apnea (per 1,000 population $)^{\ddagger}$} & \multicolumn{2}{|c|}{ Estimated number of OSA patients§ } \\
\hline & Male & Female & Male & Female & Male & Female & Male & Female \\
\hline $0-19$ & 2,163 & 1,018 & 273 & 84 & $2,202(0.47)$ & $898(0.21)$ & & \\
\hline $20-29$ & 6,845 & 1,646 & 2,008 & 268 & $6,666(1.78)$ & $1,294(0.39)$ & 142,308 & \\
\hline $30-39$ & 17,171 & 1,781 & 11,102 & 690 & $17,198(4.51)$ & $1,604(0.46)$ & 610,436 & 101,187 \\
\hline $40-49$ & 16,517 & 2,314 & 14,821 & 912 & $17,490(4.13)$ & $2,281(0.56)$ & 402,553 & 117,950 \\
\hline $50-59$ & 12,290 & 4,626 & 11,477 & 2,221 & $13,926(3.23)$ & $4,746(1.11)$ & 513,423 & 124,514 \\
\hline $60-69$ & 6,996 & 3,648 & 7,764 & 2,994 & $8,541(2.83)$ & $3,850(1.22)$ & 325,800 & 300,673 \\
\hline $70-79$ & 2,314 & 1,303 & 2,587 & 1,148 & $2,793(1.78)$ & $1,372(0.70)$ & & \\
\hline$\geq 80$ & 343 & 242 & 487 & 273 & $404(0.68)$ & $242(0.20)$ & & \\
\hline Total & 64,461 & 16,555 & 50,519 & 8,590 & $67,633(2.61)$ & $16,050(0.62)$ & & \\
\hline
\end{tabular}

Data are presented as n (\%). Number of PSG performed between July 2018 and December 2019 was presented. Number of the patients who were prescribed PAP between July 2018 and March 2020 was presented. Number of the patients who used health resource under the diagnostic codes for sleep apnea (G473) between January 2019 and December 2019 was presented. *number of the patients who received PSG between July 2, 2018 and Dec 31, 2019 was presented, ${ }^{\dagger}$ number of the patients treated with PAP between July 2018 and Mar 2020 was presented, $\neq$ number of the patients who used health resource under the diagnostic codes for sleep apnea (G473) between Jan 1, 2019 and Dec 31, 2019 was presented, §estimated from previous reports (Apnea-Hypopnea Index $\geq 15){ }^{7,8}$ PSG: polysomnography, PAP: positive airway pressure, OSA: obstructive sleep apnea 
Table 3. Regional distribution of PSG and PAP prescription

\begin{tabular}{lcrr}
\hline \multicolumn{1}{c}{ Region } & $\begin{array}{c}\text { Patients who received PSG } \\
\text { (per 1,000 population) }\end{array}$ & $\begin{array}{c}\text { Patients treated with PAP } \\
\text { (per 1,000 population) }{ }^{\dagger}\end{array}$ & $\begin{array}{r}\text { Certified sleep specialists } \\
\text { (per 100,000 population) }\end{array}$ \\
\hline Kangwon-do & $1,470(0.97)$ & $1,435(0.94)$ & $8(0.53)$ \\
Gyeonggi-do & $17,578(1.32)$ & $17,618(1.32)$ & $107(0.80)$ \\
Gyeongsangnam-do & $1,908(0.57)$ & $2,392(0.71)$ & $14(0.42)$ \\
Gyeongsangbuk-do & $887(0.33)$ & $2,082(0.78)$ & $7(0.26)$ \\
Gwangju & $2,771(1.86)$ & $1,436(0.96)$ & $22(1.48)$ \\
Daegu & $4,703(1.94)$ & $2,509(1.03)$ & $26(1.07)$ \\
Daejeon & $2,315(1.54)$ & $1,489(0.99)$ & $18(1.20)$ \\
Busan & $4,837(1.43)$ & $3,255(0.97)$ & $31(0.92)$ \\
Seoul & $31,924(3.31)$ & $14,606(1.52)$ & $112(1.16)$ \\
Sejong & $360(1.06)$ & $554(1.64)$ & $1(0.30)$ \\
Ulsan & $1,331(1.16)$ & $874(0.76)$ & $10(0.87)$ \\
Incheon & $3,075(1.04)$ & $2,845(0.96)$ & $17(0.58)$ \\
Jeollanam-do & $1,243(0.70)$ & $1,521(0.85)$ & $12(0.67)$ \\
Jeollabuk-do & $2,029(1.12)$ & $1,675(0.93)$ & $17(0.94)$ \\
Jeju-do & $1,019(1.53)$ & $773(1.16)$ & $4(0.60)$ \\
Chungcheongnam-do & $2,182(1.00)$ & $2,364(1.08)$ & $9(0.41)$ \\
Chungcheongbuk-do & $1,536(0.94)$ & $1,493(0.92)$ & $16(0.98)$
\end{tabular}

Data are presented as n (\%). *number of patients who received PSG between July 2018 and Dec 2019 was presented according to the region of health institutes, ${ }^{\dagger}$ number of the patients treated with PAP between July 2, 2018 and Mar 31, 2020 was presented according to the region of residence. PSG: polysomnography, PAP: positive airway pressure.
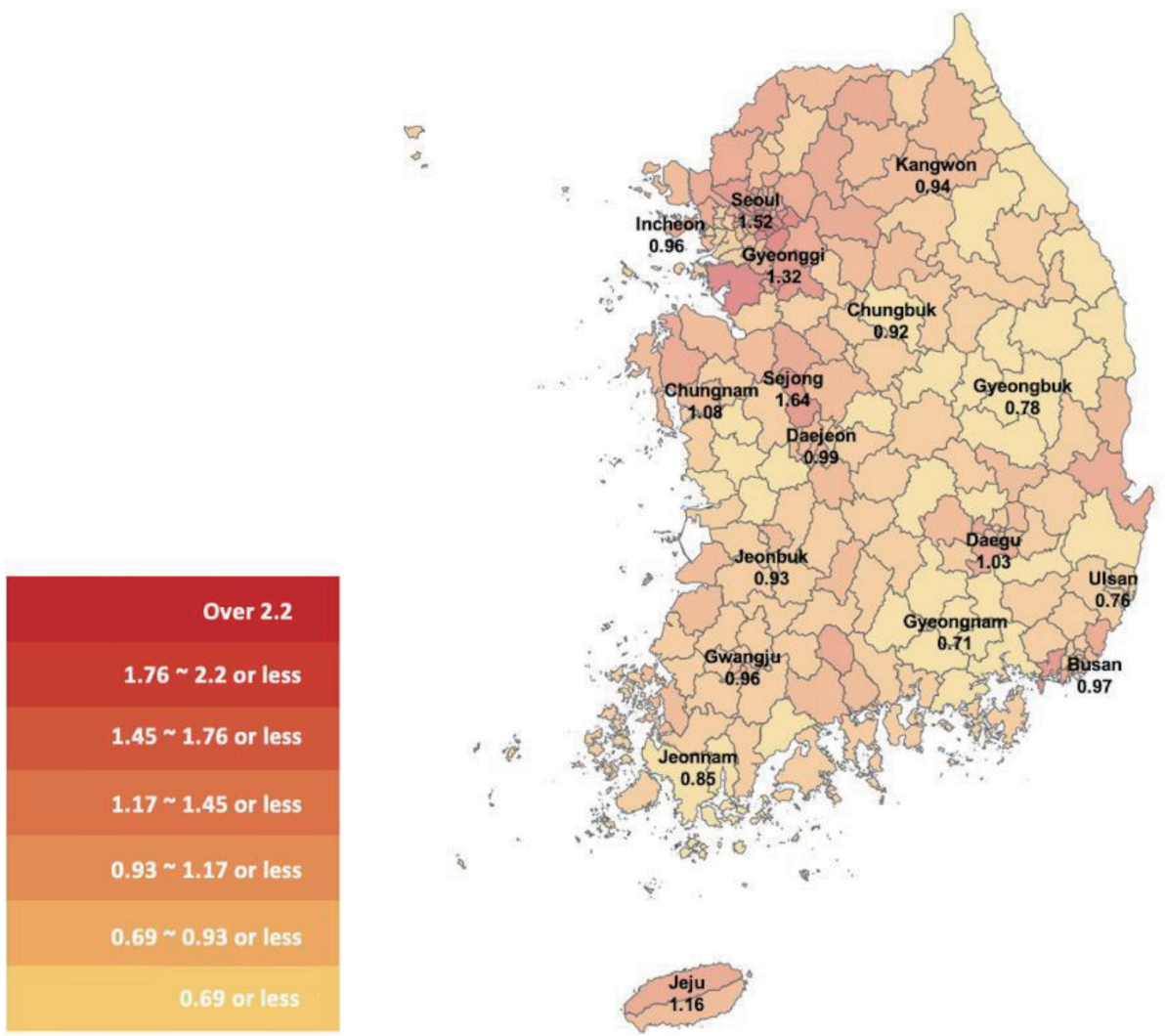

Figure 2. Geographic distribution of the patients treated with positive airway pressure (number of patients per 1,000 population) according to the patients' residential areas. 
Table 4. The number of patients treated with PAP according to the kind of institutions

\begin{tabular}{lc}
\hline \multicolumn{1}{c}{ Institution } & Number of patients \\
\hline Tertiary hospital & 16,158 \\
General hospital & 8,494 \\
Hospital & 4,783 \\
Nursing hospital & 93 \\
Clinic & 29,469 \\
Dental hospital & 112 \\
\hline
\end{tabular}

Number of the patients treated with PAP between July 2, 2018 and Mar 31, 2020 was presented. PAP: positive airway pressure

Table5. The number of patients treated with PAP according to specialty of prescribing physicians

\begin{tabular}{lc}
\hline \multicolumn{1}{c}{ Specialty } & Number of patients (per a physician) \\
\hline Otorhinolaryngology & $39,347(10.00)$ \\
Neurology & $11,040(5.81)$ \\
Psychiatry & $6,063(1.64)$ \\
Internal medicine & $2,196(0.13)$ \\
Family medicine & $242(0.04)$ \\
Pediatrics & $130(0.02)$ \\
Rehabilitation & $28(0.01)$ \\
\hline
\end{tabular}

Number of the patients treated with PAP between July 2, 2018 and March 31, 2020 was presented. Number of physicians were based on the statistics in 2019. PAP: positive airway pressure

있었고, 의원과 이비인후과 전문의의 처방이 가장 많았다.

국민건강보험 급여화는 OSAS 진료량 증가에 유의한 영향 을 끼쳤다. 2018년 7월부터 국민건강보험 급여화가 되었으므 로, 2018년은 실질적인 분석 기간이 6개월임을 감안하여야 하나, 그동안 미륐던 환자의 진료가 이루어졌을 것으로 생각 되므로, 2019년에 더 증가했다고 볼 수 있다. 하지만, 진료량 은 급증하였으나, 해당 기간에 PAP 치료를 받은 환자 수를 국내 OSAS(AHI $\geq 15$ ) 추정 환자 수에 비하면, 20 69세 남 성의 $3.2 \%, 30 \sim 69$ 세 여성에서 $1.9 \%$ 에 불과하여, 전국적으로 는 과잉 처방이 이루어졌다고 판단되지는 않는다.

PAP에 대한 3개월 내 순응도는 $69.3 \%$ 로 이전에 외국에서 보고된 40 80\%의 범위에 있었다. ${ }^{9,10}$

이번 조사에서 눈에 띄는 점은, $\mathrm{PAP}$ 치료에 있어서 $\mathrm{CPAP}$ 보다 $\mathrm{APAP}$ 를 압도적으로 많이 처방하는 경향이다. $\mathrm{APAP}$ 는 수면 기사가 수기로 PAP 적정 압력 결정하는 것을 대신하는 auto-titrating 및 하룻밤 수면 중에도 무호흡 여부에 따라 압력을 변동해 주는 auto-adjusting의 두 가지 목적을 달성 할 수 있다. Auto-titrating 측면에서 동반 질환이 없는 경우, 수기로 압력을 결정하는 데 비견할 만한 결과를 보여주었고, 하룻밤 사이에 전달되는 평균 압력은 CPAP에 비해 APAP가 낮아서, $\mathrm{CPAP}$ 에 적응을 못 하는 환자는 $\mathrm{APAP}$ 로 전환을 시
도하기도 한다. 그러나, 처음 $\mathrm{PAP}$ 를 시작할 때 수면 기사가 마스크를 맞추어 주고 어려움을 해결해 주는 과정이 생략되 므로 초기 탈락율이 높을 수 있다. 또한 심부전, 만성폐쇄성 폐질환, 중추성 수면무호흡 등의 동반 질환이 있을 때는 효 과를 보장할 수 없어 유의해야 한다. ${ }^{11}$

국민건강보험 급여 이전의 자료가 없어 장담하기는 어려 우나, 이전에 상급종합병원 위주로 이루어지던 수면 진료가 국민건강보험 급여 이후 의원이 다수를 차지하도록 판도가 변한 것을 알 수 있었다. 또한, 수면 진료의 지역적 편중이 심 한 것을 알 수 있었다. 이는 수면 의사의 밀도가 높은 지역에 서는 과잉 진료가, 수면 의사가 없는 지역에서는 진단 및 치 료가 이루어지지 않을 우려가 있다. OSAS는 진단 후 압력을 정하면 집에서 치료할 수 있기 때문에 거주지와 의료기관의 거리가 크게 문제되지 않는다. 따라서, OSAS에 대한 보편적 인 인식 개선이 필요할 것으로 보인다.

이 연구는 OSAS 진료의 실제에 대한 전 국가적인 통계로, 향후 보건행정 및 의료진의 의사결정에 중요한 근거가 될 것 이다. 이는 세계적으로 매우 희귀한 보고이며, 이를 통해 얻 은 PAP 순응도는 보편적으로 적용할 수 중요한 자료이다. 이 연구의 제한점으로, 국민건강심사평가원의 데이터베이스로 부터 산출한 수면무호흡 및 수면다원검사 진료 통계에는 건 강보험 자료만이 포함되었고, 의료 급여 자료는 포함되지 않 아 실제 수에 비해 저평가되었을 것이다. 또한 PAP 순응도는 3 개월 후 처방전을 재발급받을 때까지의 사용에 대한 평가 로, 이후의 순응도는 더 낮을 가능성이 있고, 이에 대한 평가 도 필요하다.

이 연구로 2018년 7월 국민건강보험 급여화 이후, OSAS와 관련된 의료 이용이 급증하였고 지역 간 불균형이 있음을 확인하였다. 향후, OSAS 의료의 적정성과 보편성을 위한 노 력이 필요하다.

\section{Acknowledgments}

None.

\section{Conflicts of Interest}

The authors have no potential conflicts of interest to disclose.

\section{ORCID iDs}

Moonjeong Kim https://orcid.org/0000-0002-0692-8569

Hyunjeong Baek https://orcid.org/0000-0003-1325-3392

Seo-Young Lee https://orcid.org/0000-0001-5319-1777

\section{Author Contributions}

Conceptualization: Seo-Young Lee. Data curation: Moonjeong Kim. Formal analysis: Moonjeong Kim. Investigation: Seo-Young Lee. Methodology: Seo-Young Lee. Supervision: Seo-Young Lee, Hyunjeong Baek. Writing_original draft: Moonjeong Kim. Writing_review \& editing: SeoYoung Lee, Hyunjeong Baek. 


\section{REFERENCES}

1. Franklin KA, Lindberg E. Obstructive sleep apnea is a common disorder in the population-a review on the epidemiology of sleep apnea. $J$ Thorac Dis 2015;7:1311-1322. https://doi.org/10.3978/j.issn.20721439.2015.06.11.

2. Cao MT, Guilleminault C, Kushida CA. Clinical features and evaluation of obstructive sleep apnea and upper airway resistance syndrome. In: Kryger MH, Roth T, Dement WC. Principles and practice of sleep medicine. 5th ed. St. Louis: Saunders, 2011;1206-1218. https://doi. org/10.1016/B978-1-4160-6645-3.00105-5.

3. Kaspe DL, Fauci AS, Hauser SL, Longo DL, Jameson JL, Loscalzo J. Harrison's principles of internal medicine. 20th ed. New York: McGrawHill Education, 2018;2013-2018.

4. Healthcare Bigdata Hub. Disease subdivision statistics (search with F6290 and G473) [online] [cited 2020 Sep, 15]. Available from: URL: http://opendata.hira.or.kr/op/opc/olap4thDsInfo.do.

5. Korea Statistical Information Service. Major indicators of Korea [online] [cited 2020 Sep, 30]. URL: https://kosis.kr/index/index.do.

6. Korea Statistical Information Service. Resident population by city, county, and district [online] [cited 2020 Sep, 3]. URL: http://kosis.kr/
statHtml/statHtml.do?orgId=101\&tblId=DT_1B040A3\&conn_ path=I3.

7. Tufik S, Santos-Silva R, Taddei JA, Bittencourt LR. Obstructive sleep apnea syndrome in the Sao Paulo Epidemiologic Sleep Study. Sleep Med 2010;11:441-446. https://doi.org/10.1016/j.sleep.2009.10.005.

8. Kim J, In K, Kim J, et al. Prevalence of sleep-disordered breathing in middle-aged Korean men and women. Am J Respir Crit Care Med 2004;170:1108-1113. https://doi.org/10.1164/rccm.200404-519OC.

9. Kakkar RK, Berry RB. Positive airway pressure treatment for obstructive sleep apnea. Chest 2007;132:1057-1072. https://doi.org/10.1378/ chest.06-2432.

10. Wickwire EM, Lettieri CJ, Cairns AA, Collop NA. Maximizing positive airway pressure adherence in adults: a common-sense approach. Chest 2013;144:680-693. https://doi.org/10.1378/chest.12-2681.

11. Morgenthaler TI, Aurora RN, Brown T, et al. Practice parameters for the use of autotitrating continuous positive airway pressure devices for titrating pressures and treating adult patients with obstructive sleep apnea syndrome: an update for 2007. An American Academy of Sleep Medicine report. Sleep 2008;31:141-147. https://doi.org/10.1093/ sleep/31.1.141. 